\title{
OPTIMALISASI KUALITAS PENCAHAYAAN DALAM SUATU RUANGAN BERDASARKAN PADA KESEIMBANGAN KEBUTUHAN MANUSIA, EFISIENSI ENERGI, DAN PERTIMBANGAN ARSITEKTUR DENGAN MENGGUNAKAN METODE FUZZY LOGIC CONTROL
}

\author{
Aan Ansen Andryadi' ${ }^{1}$, Ginanjar Nugraha ${ }^{2}$, \\ ${ }^{1,2}$ STMIK JABAR \\ E-mail : Ansen25@gmail.com ${ }^{1}$
}

\begin{abstract}
ABSTRAK
Kelayakan pencahayaan dalam ruangan menjadi hal yang penting untuk diperhatikan agar mata orang yang berada di dalam ruangan tersebut dapat terjaga kesehatannya. SNI 036575-2001 telah memberikan batas kelayakan pencahayaan dalam ruangan. Penelitian ini membandingkan metode fuzzy logic Tsukamoto dan Sugeno untuk menentukan intensitas kompensasi cahaya di dalam ruangan agar kualitas pencahayaan dalam ruangan menjadi optimal. Penelitian yang dilakukan mengambil beberapa sample data dari ruangan tempat penulis bekerja. Pengambilan data menggunakan sensor intensitas cahaya yang diletakan di atas meja di tengah ruangan dengan menghadap keatas/plafon ruangan. Waktu pengambilan sample data dimulai pada pukul 7 pagi sampai dengan pukul 4 sore, metode pengambilan sample data adalah dengan mengukur dua kondisi pencahayaan ruangan dan mengukur intensitas cahaya ruangan mengandalkan cahaya luar yang masuk melalui jendela dan cahaya lampu dalam ruangan dengan mengaturnya melalui saklar lampu. Hasilnya didapat kesimpulan bahwa metode fuzzy logic Sugeno memberikan hasil yang lebih baik dalam menentukan nilai intensitas kompensasi cahaya yang dibutuhkan agar ruangan tempat bekerja mendapatkan pencahayaan yang sesuai dengan standar yang disyaratkan dibandingkan metode fuzzy logic Tsukomoto.
\end{abstract}

Kata kunci : Fuzzy Logic, Metode Tsukamoto, Metode Sugeno, SNI 03-6575-2001

\section{PENDAHULUAN}

Pencahayaan dalam ruangan mutlak untuk diperhatikan agar setiap orang yang bekerja dalam ruangan tersebut dapat terjaga kesehatan khususnya kesehatan mata. Untuk dapat lebih optimal dan efisien dalam penggunaan sumber daya berkenaan dengan pencahayaan dalam ruangan, SNI 03-6575-2001 telah mencakup petunjuk teknis sistem pencahayaan buatan di dalam ruangan yang dimaksudkan untuk digunakan sebagai pegangan para perancang dan pelaksana pembangunan gedung di dalam merancang sistem pencahayaan buatan dan sebagai pegangan bagi para pemilik/pengelola gedung di dalam mengoperasikan dan memelihara sistem pencahayaan buatan didalam ruangan[1].

Intensitas pencahayaan dalam ruangan yang mengandalkan sinar matahari dapat diramalkan dan dihitung dengan menggunakan metode fuzzy logic. Pada penelitian ini membandingkan dua metode fuzzy logic yaitu metode Tsukamoto dan metode Sugeno dan hasil dari perbandingan tersebut digunakan untuk melakukan optimalisasi pencahayaan dalam ruangan yaitu ketika intensitas cahaya dalam ruangan berkurang maka lampu ruangan akan menyala. 


\section{METODE FUZZY LOGIC}

Logika fuzzy adalah metodelogi sistem kontrol pemecahan masalah yang cocok diterapkan pada sistem, mulai dari sistem yang sederhana sampai sistem yang rumit atau kompleks. Metodologi ini dapat diterapkan pada perangkat keras, perangkat lunak, atau kombinasi keduanya. Dalam logika klasik dinyatakan bahwa segala sesuatu bersifat biner, yang artinya adalah hanya dua kemungkinan yaitu benar atau $\operatorname{salah}[2]$.

\subsection{FUZZY LOGIC TSUKAMOTO}

Metode fuzzy logic Tsukamoto merupakan sebuah metode yang tertuju pada aturan yang berbentuk IF - THEN yang direpresentasikan himpunan fuzzy dengan fungsi keanggotaan yang monoton, serta kriteria dan rules yang digunakan untuk menentukan hasil akhir [3]. Dalam proses perhitungan fuzzy logic Tsukamoto memiliki beberapa tahap yaitu: tahap fuzzifikasi, tahap implikasi/penerapan rules dan tahap deffuzifikasi serta setiap tahap memiliki aturan tersendiri.

\subsection{FUZZY LOGIC SUGENO}

Metode ini dikenalkan oleh Takagi - Sugeno Kang pada tahun pada tahun 1985. Model Sugeno menggunakan fungsi keanggotaan Singleton, yaitu fungsi keanggotaan yang memiliki derajat keanggotaan 1 pada satu nilai crisp dan 0 pada nilai crisp lainnya [4]. Metode fuzzy logic Sugeno sering dikenal dengan nama metode Max - Min. Metode ini mempunyai output (konsekuen) sistem tidak berupa himpunan fuzzy melainkan berupa konstanta atau persamaan linier[5].

\section{PEMBAHASAN}

Permasalahan kelayakan pencahayaan ruangan yang memenuhi standar menjadi bahan untuk mendapatkan metode fuzzy logic yang sesuai. Pada penelitian ini kondisi pencahayaan ruangan dijadikan bahan analisa masalah untuk menguji output cahaya ruangan dengan metode fuzzy logic Tsukamoto, dan Sugeno. SNI 03-6575-2001 mensyaratkan intensitas cahaya untuk ruangan kantor yang bekerja dengan ketelitian rendah adalah 350 lumen, angka tersebut merupakan cahaya keluaran/ output (CO) target dalam penelitian ini. Penelitian yang dilakukan dengan mengambil beberapa sample data di ruangan tempat penulis bekerja, pengambilan data menggunakan sensor intensitas cahaya yang diletakan di atas meja di tengah ruangan dengan menghadap keatas/plafon ruangan. Waktu pengambilan sample data dimulai pada pukul 07:00 pagi sampai 16: 00 dengan metode pengambilan sample data adalah mengukur dua kondisi pencahayaan ruangan yang berbeda yaitu mengukur intensitas cahaya ruangan dengan mengandalkan hanya cahaya luar yang masuk melalui jendela, dan mengukur intensitas cahaya lampu dalam ruangan dengan cara mengaturnya melalui saklar lampu. 
Tabel 1. Sample data yang didapatkan

\begin{tabular}{|r|r|r|r|r|r|r|}
\hline \multirow{2}{*}{$\begin{array}{l}\text { Hasil } \\
\text { ukur }\end{array}$} & \multicolumn{2}{|c|}{1} & \multicolumn{2}{|c|}{2} & \multicolumn{2}{|c|}{3} \\
\cline { 2 - 7 } & CM & CL & CM & CL & CM & CL \\
\hline jam & & & & & & \\
\hline $7: 00$ & 72 & 96 & 88 & 112 & 456 & 184 \\
\hline $8: 00$ & 304 & 112 & 304 & 200 & 408 & 184 \\
\hline $9: 00$ & 248 & 104 & 216 & 152 & 256 & 240 \\
\hline $10: 00$ & 56 & 152 & 184 & 240 & 176 & 240 \\
\hline $11: 00$ & 168 & 176 & 128 & 192 & 120 & 344 \\
\hline $12: 00$ & 104 & 320 & 104 & 344 & 128 & 344 \\
\hline $13: 00$ & 88 & 212 & 104 & 392 & 164 & 400 \\
\hline $14: 00$ & 56 & 360 & 96 & 384 & 80 & 440 \\
\hline $15: 00$ & 56 & 360 & 40 & 504 & 24 & 592 \\
\hline $16: 00$ & 48 & 288 & 8 & 182 & 24 & 536 \\
\hline
\end{tabular}

Keterangan : $\mathrm{CM}=$ Cahaya Matahari, $\mathrm{CL}=$ Cahaya Lampu

Dari table hasil ukur diatas kemudian di visualisasikan dengan grafik pada Gambar 1.

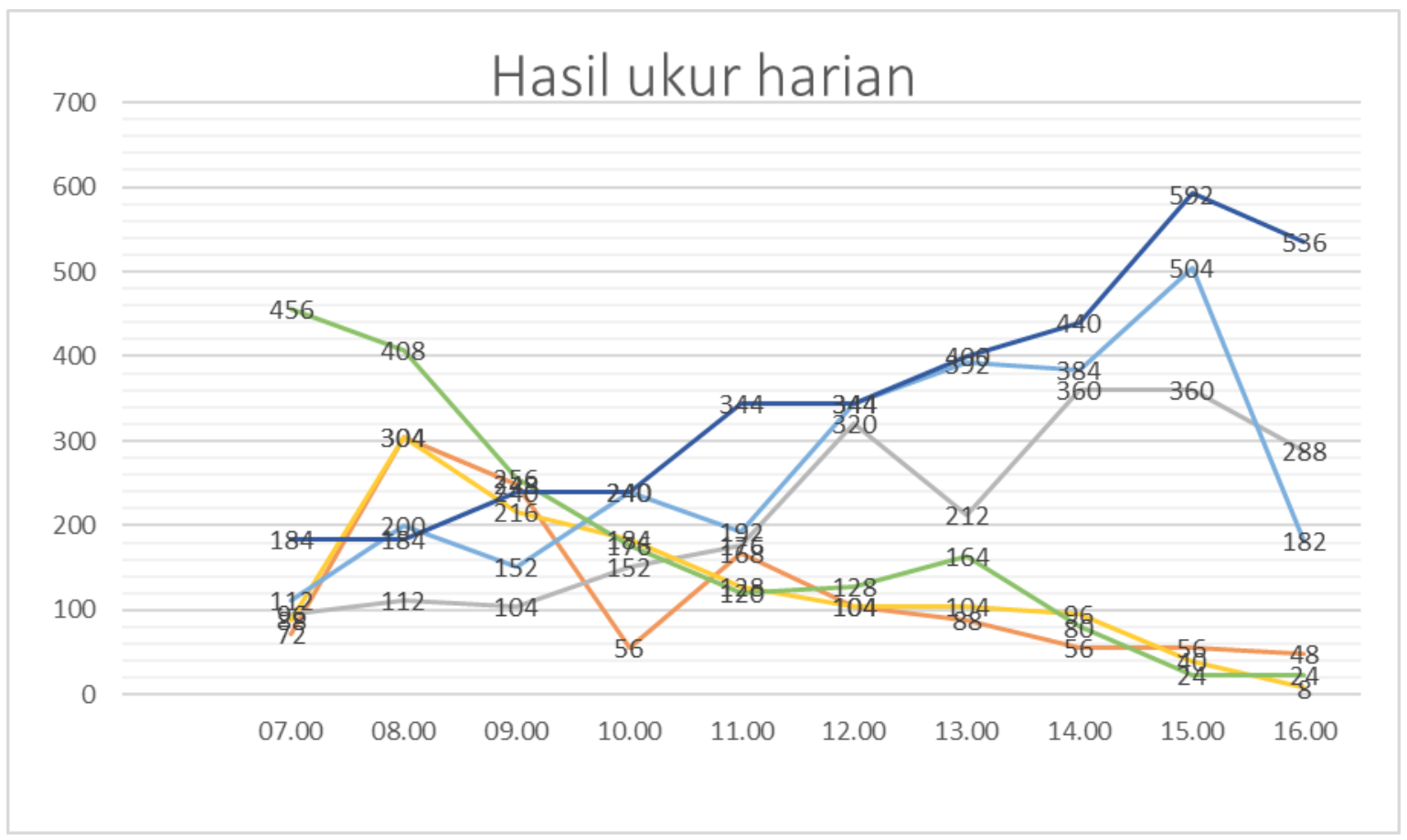

Keterangan :

\section{Gambar 1. Hasil Ukur Harian Intensitas Cahaya}

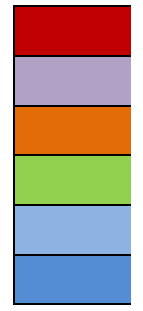

Hasil ukur -1 CM

Hasil ukur -2 CM

Hasil ukur -3 CM

Hasil ukur -1 CL

Hasil ukur -2 CL

Hasil ukur -3 CL 
Dari grafik pada Gambar 1 dapat disimpulkan sebagai berikut :

Intensitas cahaya matahari yang masuk ke dalam ruangan (CM) tertinggi adalah 456 lumen, dan terendah adalah 8 lumen. Intensitas cahaya ruangan dari penerangan buatan dengan Lampu (CL) tertinggi adalah 592 lumen dan terendah adalah 96 lumen.

\subsection{LANGKAH PENGUJIAN METODE FUZZY}

Pengelompokan variable fuzzy (Fuzzifikasi)

1. Intensitas Cahaya Masuk ruangan (CM) 8-456 lumen

2. Intensitas Cahaya Lampu dalam ruangan (CL) 96 - 592 lumen

3. Intensitas Cahaya Ouput (CO)

\subsection{MEMBUAT HIMPUNAN INPUT FUZZY}

Intensitas cahaya luar yang masuk kedalam ruangan CM

2 Himpunan Fuzzy untuk intensitas CM adalah Tinggi-Rendah

$$
Z=\frac{\sum \propto_{1} \cdot Z_{1}}{\sum \propto_{1}}
$$

$$
\begin{aligned}
& \mu[x] \text { terendah }=\left\{\begin{array}{l}
1 \frac{456-x}{350}, x<456,8 \leq x \geq 456, x>8 \\
0
\end{array}, \begin{array}{l}
0 \frac{x-8}{350} \\
11 x] \text { tertinggi }=x<456,8 \leq x \geq 456, x>8
\end{array}\right.
\end{aligned}
$$

Cahaya $\mathrm{CM}$ terendah $=(456-350) / 350=0.3$

Cahaya $C M$ tertinggi $=(350-8) / 350=0.97$

\subsection{INTENSITAS CAHAYA DALAM RUANGAN CL:}

2 Himpunan Fuzzy untuk cahaya dalam ruangan (CL) adalah Tinggi-Rendah

$$
\begin{aligned}
& \mu[\mathrm{y}] \text { terendah }=\left\{\begin{array}{l}
1 \frac{592-x}{350}, x<592,96 \leq x \geq 592, x>96 \\
0 . y] \text { tertinggi }=\left\{\begin{array}{l}
0 \\
1 \\
1
\end{array} \frac{x-96}{350}, x<592,96 \leq x \geq 592, x>96\right.
\end{array}\right.
\end{aligned}
$$

Cahaya CL terendah $=(592-350) / 350=0.69$

Cahaya CL tertinggi $=(350-96) / 350=0.71$

\subsection{BASIS PENGETAHUAN (KNOWLEDGE BASE)}

Tabel 2 Basis Pengetahuan

\begin{tabular}{|l|l|l|}
\hline \multirow{2}{*}{ CM } & \multicolumn{2}{|c|}{ CL } \\
\cline { 2 - 3 } & Rendah & Tinggi \\
\hline Rendah & Rendah & Tinggi \\
\hline Tinggi & Rendah & Tinggi \\
\hline
\end{tabular}


Fuzzifikasi dan pengelompokan variable diatas berlaku untuk melakukan defuzifikasi pada mesin inferensi yang digunakan kedalam dua metode yang dibahas dalam penelitian ini yaitu fuzzy logic metode Tsukomoto dan Sugeno.

\subsection{METODE TSUKAMOTO}

Berikut adalah control aturan (rules) dari variable fuzifikasi berdasarkan metode Tsukamoto:

1. IF cahaya CL Rendah AND cahya CM Tinggi RESULT cahaya OUT Rendah

2. IF cahaya CL Rendah AND cahaya CM rendah RESULT cahaya OUT Rendah

3. IF cahaya CL Tinggi AND cahaya CM Tinggi RESULT cahaya OUT Tinggi

4. IF cahaya CL Tinggi AND cahaya CM Rendah RESULT cahaya OUT Tinggi

Selanjutnya menghitung nilai keanggotaan himpunan masing-masing variable dari $\alpha$ predikat $\mathrm{Z}$ dari tiap aturan (rule). Pada metode Tsukamoto, komposisi menggunakan fungsi inferensi menggunakan MIN yaitu dengan cara mengambil nilai minimum dari variabel input sebagai outputnya.

Rule : 1

cahaya $C L$ Rendah $=0.69$; cahya $C M$ Tinggi $=0.97$;

$\alpha$ - predikat- $1=0.69$

$\mathrm{Z} 1=\frac{592-Z}{350}=0.69 ; \mathrm{Z} 1=350.5$

Rule : 2

cahaya $C L$ Rendah $=0.69$; cahaya $C M$ rendah $=0.3$;

$\alpha$ - predikat $-2=0.3$

$\mathrm{Z} 2=\frac{456-Z}{350}=0.3 ; \mathrm{Z} 2=351$

Rule : 3

cahaya $C L$ Tinggi $=0.71$; cahaya $C M$ Tinggi $=0.97$

$\alpha$ - predikat-3 $=0.71$

$\mathrm{Z} 1=\frac{\mathrm{Z}-96}{350}=0.71 ; \mathrm{Z} 1=344.5$

Rule : 4

cahaya CL Tinggi=0.71; cahaya CM Rendah $=0.3$

$\alpha$ - predikat- $4=0.3$

$\mathrm{Z} 4=\frac{\mathrm{Z}-456}{350}=0.3 ; \mathrm{Z} 4=561$

Menghitung $\mathrm{Z}$ akhir dari rata-rata berbobot nilai variable $\mathrm{Z}$ (defuzzier):

$\underline{(\alpha-\text { predikat }-1 * Z 1)+(\alpha-\text { predikat }-2 * Z 2)+(\alpha-\text { predikat }-3 * Z 3)+(\alpha-\text { predikat }-4 * Z 4)}$ $\alpha$-predikat-1+ $\alpha$-predikat-2+ $\alpha$-predikat $-3+\alpha-$ predikat -4

$\frac{(0.69 * 350.5)+(0.3 * 351)+(0.71 * 344.5)+(0.3 * 561)}{0.69+0.3+0.71+0.3}$

$0.69+0.3+0.71+0.3$ 
$\mathrm{Z}=\frac{241.8+105.3+244.6+168.3}{2}=380$ lumen

\subsection{METODE SUGENO}

Pada metode Sugeno atauran (rules) nya sebagai berikut:

a. IF cahaya CL Rendah AND cahya CM Tinggi RESULT cahaya OUT = cahaya $\mathrm{CL}-\mathrm{CM}$

b. IF cahaya CL Rendah AND cahaya CM rendah RESULT cahaya OUT = cahaya $\mathrm{CL}$

c. IF cahaya CL Tinggi AND cahaya CM Tinggi RESULT cahaya OUT= cahaya CL

d. IF cahaya CL Tinggi AND cahaya CM Rendah RESULT cahaya OUT = $1.25 *$ cahaya CL-CM

Menhitung $\alpha$-predikat $\mathrm{z}$ dari tiap aturan (rule)

Rule : 1

cahaya CL Rendah $=0.69$; cahya CM Tinggi $=0.97$;

$\alpha$ - predikat- $1=0.69$

$\mathrm{Z1}=592-456$

$=136$

Rule : 2

cahaya CL Rendah $=0.69$; cahaya $\mathrm{CM}$ rendah $=0.3$;

$\alpha$ - predikat- $2=0.3$

$\mathrm{Z2}=592$

Rule : 3

cahaya $\mathrm{CL}$ Tinggi $=0.71$; cahaya $\mathrm{CM}$ Tinggi $=0.97$

$\alpha$ - predikat $-3=0.71$

$\mathrm{Z1}=592$

Rule : 4

cahaya $\mathrm{Cl}$ Tinggi $=0.71$; cahaya $\mathrm{CM}$ Rendah $=0.3$

$\alpha$ - predikat- $4=0.3$

$\mathrm{Z} 4=1.25^{*} 592-456$

$\mathrm{Z} 4=163$

Menghitung $\mathrm{Z}$ akhir dengan rata-rata berbobot dari Z (defuzzier):

$$
\begin{aligned}
& \frac{(\alpha-\text { predikat }-1 * Z 1)+(\alpha-\text { predikat }-2 * Z 2)+(\alpha-\text { predikat }-3 * Z 3)+(\alpha-\text { predikat }-4 * Z 4)}{\alpha-\text { predikat }-1+\alpha-\text { predikat }-2+\alpha-\text { predikat }-3+\alpha-\text { predikat }-4} \\
& \frac{(0.69 * 136)+(0.3 * 592)+(0.71 * 592)+(0.3 * 163)}{0.69+0.3+0.71+0.3} \\
& Z=\frac{93.8+177.6+420.3+48.9}{2}=370.3 \text { lumen }
\end{aligned}
$$

Implementasi metode fuzzy Tsukamoto dan Sugeno terhadap hasil pengukuran ratarata harian dan total rata-rata harian. 
Tabel 3. Rata-rata

\begin{tabular}{|c|c|c|c|}
\hline & \multicolumn{2}{|c|}{ RATA-RATA } & \\
\hline & CM & CL & TOTAL \\
\hline $7: 00$ & 205.3 & 130.7 & 168.0 \\
\hline $8: 00$ & 338.7 & 165.3 & 252.0 \\
\hline $9: 00$ & 240.0 & 165.3 & 202.7 \\
\hline $10: 00$ & 138.7 & 210.7 & 174.7 \\
\hline $11: 00$ & 138.7 & 237.3 & 188.0 \\
\hline $12: 00$ & 112.0 & 336.0 & 224.0 \\
\hline $13: 00$ & 118.7 & 334.7 & 226.7 \\
\hline $14: 00$ & 77.3 & 394.7 & 236.0 \\
\hline $15: 00$ & 40.0 & 485.3 & 262.7 \\
\hline $16: 00$ & 26.7 & 335.3 & 181.0 \\
\hline
\end{tabular}

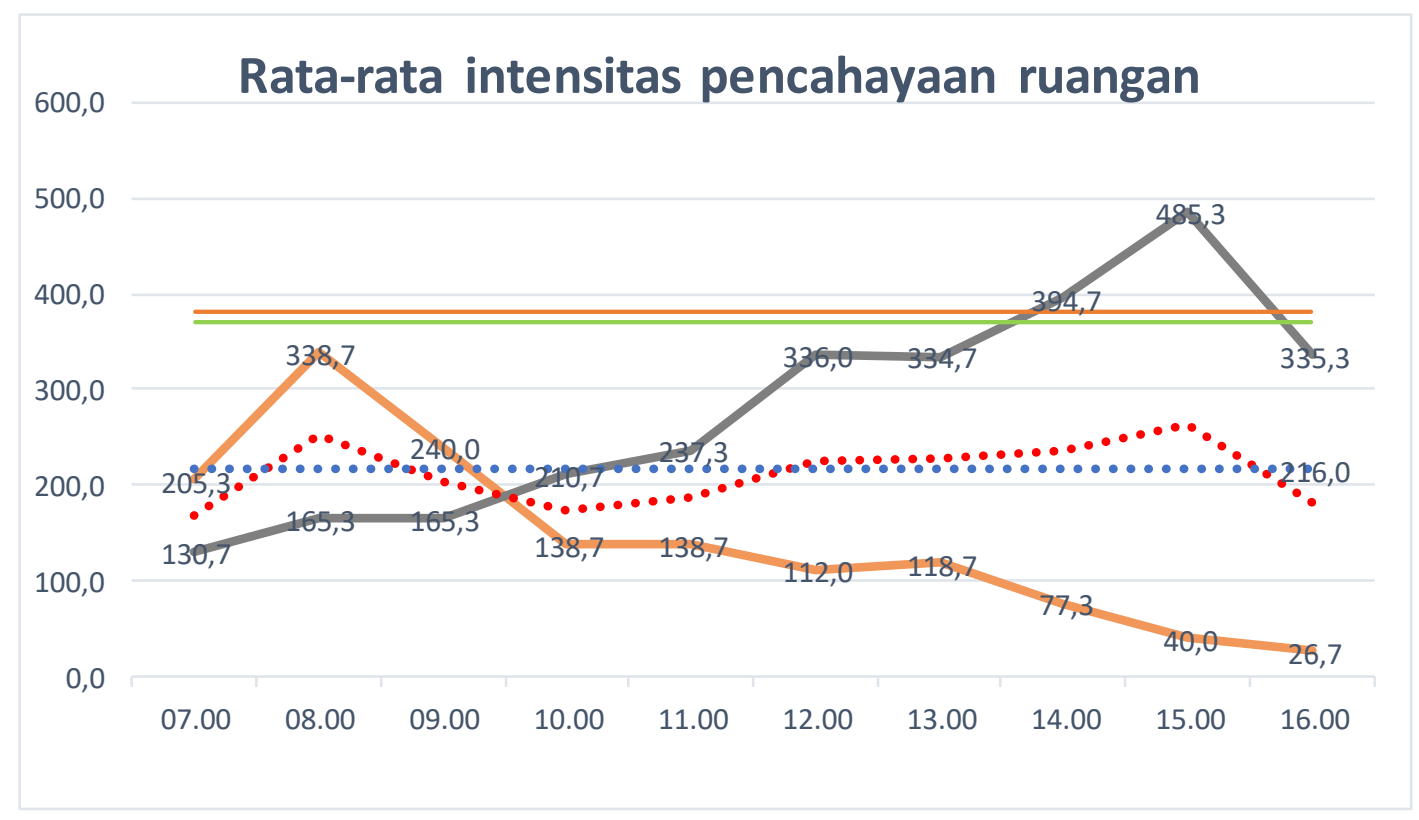

Gambar 2. Rata-rata Intensitas Pencahayaan Ruangan

Rata-Rata harian CL

Rata-Rata harian CM

Rata-Rata Total

Rata-Rata harian total

Hasil Metode Tsukamoto

Hasil Metode Sugeno 


\section{KESIMPULAN}

Metode fuzzy Sugeno memberikan hasil yang lebih baik dibandingkan metode Tsukamoto dalam menentukan nilai intensitas kompensasi cahaya yang dibutuhkan agar ruangan tempat kerja mendapatkan pencahayaan yang sesuai dengan standar yang disyaratkan(mendekati standar SNI), yaitu $370.3-216=154.3$ lumen. Sedangkan metode fuzzy Tsukamoto yaitu $380-216=164$ lumen .

\section{DAFTAR PUSTAKA}

[1] N. E. Code, I. E. Society, I. E. Commission, and A. Standard, "Tata cara perancangan sistem pencahayaan buatan pada bangunan gedung .," pp. 1-32, 2019.

[2] A. A. Caraka, H. Haryanto, D. P. Kusumaningrum, S. Astuti, F. I. Komputer, and U. D. Nuswantoro, "Logika Fuzzy Menggunakan Metode Tsukamoto Untuk Prediksi Perilaku Konsumen Di Toko Bangunan," Techno.COM, vol. 14, no. 4, pp. 255-265, 2015, [Online]. Available:

http://publikasi.dinus.ac.id/index.php/technoc/article/view/970.

[3] R. N. C. Devi, S. T. Safitri, and Fahrudin Mukti Wibowo, "PENERAPAN METODE FUZZY LOGIC TSUKAMOTO DALAM PENENTU ALAT KONTRASEPSI," Bianglala Inform., vol. 3, no. 1, pp. 229-236, 2018.

[4] R. Y. Kartikasari, "Optimization of Traffic Light Control Using Fuzzy Logic Sugeno Method,” Int. J. Glob. Oper. Res., vol. 1, no. 2, pp. 51-61, 2020, doi: 10.47194/ijgor.v1i2.37.

[5] M. Simanjuntak, "Penilaian Kinerja Dosen Menggunakan Metode Sugeno," J. Liq., vol. 4, no. 1, pp. 100-109, 2017. 